\title{
ALGUMAS CONSIDERAÇÕES SOBRE OS LETRAMENTOS ACADÊMICOS NO CONTEXTO BRASILEIRO
}

\author{
Raquel Salek FIAD \\ (UNICAMP) \\ racafiad@gmail.com
}

Resumo: Com base nas discussões teóricas dos Novos Estudos do Letramento, os estudos sobre as práticas de escrita no contexto acadêmico ganharam uma nova dimensão. No contexto brasileiro, alguns desses estudos tem se aproximado de outras teorias, como as dos estudos do texto e do discurso com o objetivo de discutir questões sobre o letramento acadêmico.

Palavras-chave: Letramento acadêmico. Práticas de letramento. Novos Estudos do Letramento.

\section{CONSIDERATIONS ABOUT ACADEMIC LITERACIES IN THE BRAZILIAN CONTEXT}

Abstract: Studies about literacy practices in the academic context have improved their theoretical basis due to the New Literacy Studies. In the Brazilian context, some studies try to join the academic literacy perspective to discourse and text theories.

Keywords: Academic literacy. Literacy practices. New Literacy Studies. 


\section{Indrodução}

Neste texto apresento algumas questões sobre estudos na área de letramentos acadêmicos no contexto brasileiro. Para conduzir essas questões, começo com uma breve contextualização sobre a introdução do conceito de letramento no país. Em seguida, apresento alguns conceitos e algumas propostas desenvolvidos no interior das discussões sobre os Novos Estudos do Letramento e o letramento acadêmico por teóricos que vem se dedicando ao assunto nas últimas décadas. Finalmente coloco as questões que considero pertinentes para pensarmos os estudos de letramento no contexto acadêmico no país.

\section{1 - O conceito de letramento no país}

É recorrência nos estudos sobre letramento que a primeira menção a esse termo, no Brasil, foi no livro "No mundo da escrita - uma perspectiva psicolinguística", de Mary Kato, em 1986. Nesse livro, a autora já relacionava o conceito com a alfabetização, mesmo de modo pouco explícito, ao dizer que é função da escola introduzir a criança no mundo da escrita, tornando-a um cidadão funcionalmente letrado.

Outro texto dessa década foi a tese de doutorado de Leda Tfouni, publicada como livro em 1988 (Adultos não-alfabetizados: o avesso do avesso), em que o conceito de letramento foi tratado em relação a adultos considerados nãoalfabetizados.

Nesses textos e em outros desse período, a distinção entre letramento e alfabetização é uma constante. O artigo de Magda Soares, "O que é letramento?", de 1996, posteriormente publicado no livro "Letramento - um tema em três gêneros" (Soares, 1998), enfatiza a relação entre letramento e alfabetização. Para Soares, ser alfabetizado, ter adquirido a tecnologia da escrita, é diferente de usar a escrita socialmente. Além disso, para essa autora, a escrita possibilitaria mudanças ou consequências tanto cognitivas como sociais por parte de quem a utiliza.

Já Kleiman (1995) incorpora a perspectiva de letramento como prática social, a partir de seu contato com estudos que apontavam essa visão. No 
entanto, mesmo adotando essa perspectiva, que ultrapassa o que acontece no contexto escolar e se refere à sociedade como um todo, a relação entre o conceito de letramento e o de alfabetização está presente.

Resumindo a inserção do conceito a partir da década de 1980, podemos dizer que o conceito de letramento passa a fazer parte das discussões educacionais no país, dialogando com o conceito de alfabetização, em si já polêmico, principalmente quando se trata de estabelecer critérios entre 0 alfabetizado e o analfabeto.

Conforme apresenta Andrade (2010, p.5),

$\mathrm{Na}$ década de 90 , desembarca no campo da educação uma perspectiva teórica sobre a língua escrita, sob o rótulo de estudos de Letramento. Estes já vinham sendo desenvolvidos em diversas áreas das ciências humanas (Antropologia, Estudos Etnográficos, História Cultural, Sociologia da leitura), mas no Brasil os caminhos que tomaram rumavam para a disposição de dialogar com o que vinha sendo feito em termos de alfabetização nas escolas.

$\mathrm{Na}$ difusão do conceito, vinha pressuposta a separação entre os processos de alfabetização e de letramento, e preconizando-se sua junção. Dizia-se que "deve-se alfabetizar letrando", o que pressupostamente implica em se pensar que estes processos andavam até aquele momento separados. Por se ter focalizado nesta dicotomização, buscando-se didaticamente indicar a separação dos termos alfabetização e letramento para preconizar a sua junção, os efeitos que se acabou provocando foram indesejáveis, os de não entendimento da relevância da perspectiva em si.

Essa entrada, no país, do conceito de letramento, em dicotomia com conceito já corrente de alfabetização, acontece no momento em que estudiosos já propunham uma visão de letramento como um fenômeno social, distanciando-se da concepção mais calcada no indivíduo e apoiada em crenças e concepções que começaram a ser relativizados e criticados.

\section{2 - Os novos estudos do letramento}

Opondo-se à concepção dicotômica entre oralidade e escrita, questionando a visão de que a presença da escrita provocaria impactos e consequências nas sociedades e nos indivíduos, derrubando a crença na supremacia da escrita e das sociedades que possuíam a escrita em oposição às sociedades ágrafas, foi proposto o que os estudiosos denominaram Novos Estudos do Letramento (NEL). 
Street (1984), um dos autores responsáveis por essa concepção de letramento, apresenta críticas à concepção de escrita da cultura ocidental, que privilegia os gêneros do discurso das classes dominantes, deixando à margem outros gêneros. Essa concepção considera a escrita e a leitura como neutras, independentes dos processos sociais, históricos e culturais.

Os Novos Estudos do Letramento, em contraposição a essas concepções, entendem o letramento como prática social, dependente dos contextos sociais nos quais a língua escrita se inscreve. Street (2003) argumenta contra as abordagens que consideravam que 0 letramento em si provocaria desenvolvimento e propõe outra perspectiva para o letramento, baseada em contribuições oferecidas pelos métodos etnográficos e que denomina de modelo ideológico do letramento.

Esse modelo entende que há diferentes usos sociais da linguagem e que os significados atribuídos à escrita e à leitura são dependentes dos contextos sociais. Consequentemente, não há um letramento, mas múltiplos letramentos, a depender dos significados atribuídos por diferentes grupos sociais. Essa concepção de letramento é sustentada a partir de estudos etnográficos realizados em vários contextos no mundo e é distinta do que Street denomina de modelo autônomo do letramento, que privilegia as habilidades técnicas, supostamente uniformes em todos os contextos. Essa distinção estabelecida vai ser fundamental para as discussões em contextos de ensino de linguagem, desde a alfabetização até o contexto universitário, que é o foco deste texto.

No interior das propostas dos Novos Estudos do Letramento, dois conceitos são fundamentais e orientam, desde então, boa parte das pesquisas desenvolvidas sobre letramentos: eventos e práticas de letramento. O conceito "evento de letramento" foi proposto por Heath (1982), que o descreveu como uma situação em que o texto escrito está presente e é em torno dele que as interações acontecem. Os eventos de letramento representam ocasiões concretas nas quais a língua escrita medeia as interações e os processos interpretativos dos participantes.

Como Street (2003) argumenta, o conceito de evento de letramento é muito interessante por permitir aos pesquisadores focalizar uma situação específica em que aconteça a leitura e/ou a escrita e observá-la, buscando caracterizá-la. No entanto, ele é insuficiente por apenas descrever, sem buscar os significados que 
são atribuídos à leitura e à escrita nessa situação. Por essa razão, ele propôs o conceito de "prática de letramento", como complementação, para dar conta das formas de pensar, agir, conceber a leitura e a escrita nos diferentes eventos de letramento. As práticas de letramento são, pois, modos culturais de utilizar a escrita, envolvem o significado que é atribuído pelos participantes e pela instituição à atividade ou à tarefa de leitura e escrita em um contexto interacional específico.

\section{3 - O conceito de letramento acadêmico, questões e propostas}

A partir da concepção do letramento como um conjunto de práticas sociais situadas - desenvolvida no interior dos NEL - alguns estudiosos começaram a focar o contexto acadêmico, com o objetivo de compreender as práticas aí presentes, compreendendo que há práticas específicas desse contexto, dada a concepção de múltiplos letramentos. Esse foco de estudos ganhou grande impulso em vários centros de pesquisa não só por razões inerentes à concepção de letramentos múltiplos mas também por motivações políticas e sociais, destacando-se a expansão do ensino superior, não só em quantidade de alunos mas também e principalmente em diversidade cultural e linguística (FIAD, 2013). Essa vertente de estudos dos NEL, iniciada por pesquisadores do Reino Unido, é denominada de Letramentos Acadêmicos.

Dentre os estudos dos Letramentos Acadêmicos realizados a partir de então, destaco o estudo de Lea e Street (1998). Os autores fizeram um estudo das práticas de escrita em contexto universitário e propuseram três modelos para explicar as diferentes práticas encontradas. Esse estudo foi muito significativo quando foi realizado e permite, até hoje, um olhar crítico e questionador para os eventos e práticas de letramento não só no contexto universitário mas para o contexto acadêmico entendido de modo mais amplo, envolvendo, por exemplo, publicações em periódicos científicos e eventos científicos como conferências e congressos. Os três modelos não são excludentes, mas se complementam, principalmente quando se observam práticas em disciplinas que se preocupam com o ensino de leitura e de escrita na universidade. Resumidamente apresento os três modelos porque a repercussão que tiveram em estudos posteriores foi grande. O modelo das habilidades compreende o letramento como um conjunto 
de habilidades individuais e cognitivas que os alunos têm de aprender e desenvolver, a fim de transferi-las para os contextos mais amplos da universidade. Esse modelo desconsidera a trajetória anterior de letramento do aluno e, ao constatar o que o aluno não sabe em relação ao letramento esperado na academia, considera o aluno como deficitário, ou seja, o aluno é visto a partir daquilo que ele não sabe e precisa aprender. No modelo da socialização acadêmica, o professor é o responsável por introduzir os alunos na cultura acadêmica, com o intuito de que eles assimilem os modos de falar, raciocinar, interpretar e usar as práticas de escrita valorizadas nas disciplinas e áreas temáticas da universidade. Nesse modelo, há uma preocupação em ensinar o que o aluno não sabe, com foco nas necessidades dos diferentes cursos. Já o modelo do letramento acadêmico, que espelha a visão defendida pelos autores do artigo, adota uma perspectiva de entender os significados que os sujeitos que estão na academia atribuem ao que nela acontece em termos de leituras e escritas. A interpretação dessas práticas é orientada por questões epistemológicas envolvendo as relações que os sujeitos estabelecem com o conhecimento, as relações de poder envolvidas na produção e divulgação do conhecimento e as questões de identidade.

O modelo de letramento acadêmico é discutido desde então por estudiosos que questionam, de algum modo, como é possível assumir as concepções desse modelo, que parte de perspectivas etnográficas, no contexto acadêmico, onde as convenções estão presentes. Como seria possível a inserção, no letramento acadêmico, de sujeitos que têm histórias de letramentos variadas, com práticas de leitura e escrita variadas, considerando as relações de poder e os conflitos existentes?

Apresento, a seguir, outros estudos dos Letramentos Acadêmicos de modo a ilustrar algumas das discussões que vem sendo feitas no interior dessa perspectiva. Esses estudos refletem uma das grandes questões decorrentes da perspectiva dos Letramentos Acadêmicos que é a possibilidade de aplicabilidade desse modelo ao ensino de escrita e leitura. Os estudos tentam, em princípio, apresentar uma resposta às críticas recebidas à falta de propostas pedagógicas.

Lillis, T. \& Scott, M. (2007), manifestando essa preocupação, apresentam as diferenças entre uma abordagem normativa e uma abordagem transformadora, defendendo esta última, como possibilidade de atitude no contexto acadêmico. 
Segundo as autoras, uma abordagem normativa pressupõe homogeneidade da população estudantil, estabilidade das disciplinas e unilateralidade na relação professor-aluno. Nesse quadro, o objetivo prioritário é identificar as convenções acadêmicas e ensiná-las para que os alunos se tornem proficientes. A elaboração de material didático seguiria esse objetivo. Já uma abordagem transformadora não exclui essas questões mas também se preocupa com:

a) localização de tais convenções em relação a tradições específicas e controvertidas da tomada de conhecimento b) fomentando a perspectiva de escritores (sejam estudantes ou profissionais) no sentido em que tais convenções incidem sobre a sua construção de significados; $c$ ) explorando modos alternativos da construção de significados na academia, considerando os recursos que (estudantes) escritores trazem para a academia como ferramentas legítimas para a construção de significados (LILLIS \& SCOTT, 2007, p 12-13).

Ursula Wingate and Chris Tribble (2012), em um artigo com o título de "The Best of Both Worlds? Towards an EAP/Academic Literacies Writing Pedagogy", defendem que apenas uma abordagem no modelo do letramento acadêmico não seria suficiente pois os Letramentos acadêmicos focam nas práticas e não nos textos. Argumentam que o modelo precisa ser combinado com ensino com base no texto a fim de desenvolver o nível de consciência de gênero necessário para que os alunos sejam bem sucedidos na escrita acadêmica.

Mais recentemente, Lea e Street, em um artigo que será publicado em breve - 'Academic Literacies 15 years on' - perguntam por que o artigo de 1998 teve tanta repercussão considerando a polêmica criada entre os modelos tradicionais de ensino de escrita na universidade e o modelo dos letramentos acadêmicos. No artigo, reafirmam a relevância da discussão sobre práticas de escrita no contexto acadêmico devido fundamentalmente ao fracasso dos modelos de ensino existentes especialmente para estudantes que estão tendo acesso ao ensino superior devido à expansão que esse ensino teve nas últimas décadas. Reafirmam a crítica aos modelos que tem uma concepção de que os alunos são deficitários e que não incorporam a diversidade de letramentos.

Esses estudos ilustram como a perspectiva dos Letramentos Acadêmicos vem sendo discutida na relação com as propostas pedagógicas. Os autores mostram que, apesar de não ter uma proposta delineada detalhadamente, os Letramentos Acadêmicos permitem pensar o ensino da escrita a partir de princípios 
transformadores que envolvem as relações que os sujeitos têm com o conhecimento e as relações de poder presentes no contexto de ensino.

\section{4 - O letramento acadêmico no contexto brasileiro}

Marinho, M. (2010) apontou que a escrita acadêmica não teria recebido, até aquele momento, a devida atenção por parte de estudiosos brasileiros, diferentemente do que já acontecia em relação ao ensino-aprendizagem da escrita no ensino médio e fundamental.

Concordando com Marinho, gostaria de fazer uma reflexão breve entre a relação de estudos brasileiros sobre a escrita escolar e alguns estudos que estão sendo feitos na última década na perspectiva dos Letramentos Acadêmicos. Considero que a grande quantidade de estudos sobre escrita escolar desenvolvida no Brasil desde a década de 1980, com base em referenciais teóricos advindos dos estudos do texto e do discurso, somados hoje aos estudos dos Letramentos Acadêmicos, nos possibilita pensar, hoje, na escrita acadêmica,

a partir do que foi possível construir como críticas, reflexões e propostas durante esses mais de 30 anos de pesquisas. Com isso quero dizer que é possível pensarmos no letramento acadêmico tentando articular concepções teóricas advindas dos Letramentos Acadêmicos com concepções teóricas advindas de estudos do texto e do discurso. Considero essa perspectiva como uma contribuição que os estudos brasileiros podem dar aos estudos da escrita no contexto acadêmico. Nessa direção, apresento alguns caminhos que vejo, hoje, na pesquisa brasileira.

Uma das contribuições vindas dos estudos do letramento à nossa tradição de pesquisas sobre a escrita é trazer a perspectiva etnográfica como uma possibilidade de construir uma articulação entre o texto e o contexto na abordagem da escrita. Essa preocupação está presente no artigo de Lillis (2008), em que critica a separação, nas pesquisas, entre o texto e o contexto. Defende que etnografia não seja entendida como um método, mas como uma "teorização" para permitir a articulação entre o texto e o contexto na produção da escrita. $O$ conceito chave proposto por Lillis, nesse artigo, é o conceito de "história do texto", utilizado nos seus estudos da escrita acadêmica, especialmente nas interações entre alunos e professores e entre acadêmicos e revisores. Vejo a perspectiva proposta por Lillis como muito produtiva para estudos que possam vir a ser 
realizados no Brasil envolvendo diversos tipos de interações em torno de escritas acadêmicas. O trabalho de Pasquotte-Vieira e Fiad (2014) é uma tentativa de aliar a perspectiva etnográfica a uma perspectiva dialógica para a análise de um evento de letramento caracterizado como qualificação de mestrado.

Um outro conjunto de estudos sobre escrita acadêmica no Brasil constituído com articulação dos estudos dos letramentos acadêmicos com a perspectiva bakhtiniana de estudo da linguagem são os estudos de Fischer (2010) e Fischer e Pelandré (2010).

Nesses estudos, a concepção dialógica da linguagem tem sido a base para análise da escrita em situações de letramento acadêmico. Os estudos de Fischer (2010) e de Fischer e Pelandré (2010) propõem o modelo dialógico dos letramentos acadêmicos no processo de constituição letrada de estudantes universitários, mostrando como isso acontece nas interações entre estudantes e docentes.

Essa abordagem dialógica da escrita acadêmica considerando também a perspectiva dos letramentos acadêmicos aproxima-se do quadro exposto por Lillis 2003. A autora critica as abordagens - que podem ser chamadas de tradicionais do ensino de escrita acadêmica por terem uma perspectiva monológica, calcada no modelo autônomo de letramento. Essas abordagens carregam as características do modelo autônomo explicitadas acima, dentre elas a perspectiva deficitária da escrita dos alunos. Por outro lado, embora reconheça que a perspectiva do modelo dos letramentos acadêmicos pode contribuir para a construção de alternativas a essa abordagem monológica, critica a falta de propostas. Daí a proposta de uma abordagem dialógica, no quadro do modelo dos letramentos acadêmicos. Dialogismo, nesse quadro, sendo entendido como um objetivo a ser trabalhado, nas práticas de letramento acadêmicas.

No entanto, a articulação entre teorias de base discursiva e teorias que se baseiam em uma perspectiva etnográfica (como os estudos dos letramentos acadêmicos) é conflituosa, como aponta Corrêa (2010). A partir da análise de Street (2009) de que existem aspectos que ficam ocultos mas poderiam ter sido explicitados durante o processo de escrita dos alunos, Corrêa (2010, p. 333) propõe "uma reordenação $\mathrm{d}[\mathrm{a}]$ perspectiva etnográfica para mostrar que a observação das práticas discursivas em formulações textuais particulares permite reconhecer aspectos da trama das relações intergenéricas na composição do 
texto. O objetivo é destacar a contribuição da perspectiva discursiva para a obtenção e análise de dados tais como os obtidos pela pesquisa etnográfica".

Destaquei, neste artigo, pesquisas brasileiras que tentam se aproximar dos estudos dos Letramentos Acadêmicos, rediscutindo esses estudos a partir de outras vertentes teóricas que tem orientado estudos sobre a escrita não só no contexto acadêmico. Minha intenção foi mostrar como essa tentativa pode ser muito produtiva ao aproximar teorias, discutindo-as, propondo mudanças e construindo outras possibilidades de análises, além de ser uma contribuição de nossas pesquisas para uma discussão que acontece em muitos centros de pesquisa.

\section{Referências}

ANDRADE, L. T. O professor alfabetizador imantado entre propostas teóricas: o letramento e a metodologia do fônico. Anais do I SIHELE - Seminário Internacional sobre História do ensino de leitura e escrita. A constituição do campo da história da alfabetização no Brasil, Marília, 2010.

CORRÊA, M. L. G. As perspectivas etnográfica e discursiva no ensino da escrita: o exemplo de textos de pré-universitários. Revista da ABRALIN, v. Eletrônico, n. Especial, p. 333-356, 2ª parte 2011.

FIAD, R.S. Reescrita, Dialogismo e Etnografia. Revista Linguagem (em) Discurso, Tubarão, SC, v. 13, n. 3, p. 463-480, set./dez. 2013.

FISCHER, A. \& PELANDRÉ, N. Letramento acadêmico e a construção de sentidos nas leituras de um gênero. Perspectiva, Florianópolis, v. 28, n. 2, 569599, jul./dez. 2010.

FISCHER, A. Sentidos situados em eventos de letramento na esfera acadêmica. Educação, Santa Maria, v. 35, n. 2, p. 215-228, maio/ago. 2010.

HARRINGTON, K. (Eds.) Working with Academic Literacies: Research, Theory, Design, Bingley Emerald, (a sair).

HEATH, S.B. Ways with words. Cambridge: Cambridge University Press, 1983.

KATO, M. No mundo da escrita. Uma perspectiva psicolinguística. São Paulo: Ática, 1986.

KLEIMAN, A. B. (Org.). Os significados do letramento: uma nova perspectiva sobre a prática social da escrita. Campinas, SP: Mercado de Letras, 1995. 
LEA, M. R.; STREET, B. Student Writing in higher education: an academic literacies approach. In: Studies in Higher Education. London, v. 23, n. 2, p. 15716, June, 1998.

. Academic Literacies 15 years on. In: LILLIS, T.; LEA, M.; MITHELL, S.;

LILLIS, T. Student Writing as 'Academic Literacies': Drawing on Bakhtin to Move from Critique to Design. Language and Education 17, 3: 192-207, 2003.

. Ethnography as Method, Methodology, and "Deep Theorizing": Closing the gap between text and context in Academic Writing Research. Written Communication, 2008.

LILLIS, T; SCOTT, M. Defining academic literacies research: Issues of epistemology, ideology and strategy. Journal of Applied Linguistics, London, 4, p. 5-32, 2007.

MARINHO, M. A escrita nas práticas de letramento acadêmico. Revista Brasileira de Linguística Aplicada, v. 10, n. 2, p. 363-386, 2010.

PASQUOTTE-VIEIRA, E.; FIAD, R.S. Letramentos acadêmicos: entre práticas letradas acadêmicas e não acadêmicas. A sair em Linguagem e Ensino.

SOARES, M. Letramento em três gêneros. Belo Horizonte: Autêntica, 1998.

STREET, B. V. Literacy in theory and practice. London: Cambridge University Press, 1984.

Abordagens alternativas ao letramento e desenvolvimento. Artigo apresentado durante a Teleconferência UNESCO Brasil sobre letramento e diversidade, 2003.

"Hidden" features of academic paper writing. Working Papers in Educational Linguistics, 24/1, 2009. p. 1-17.

TFOUNI, L. Adultos Não-Alfabetizados: 0 Avesso do Avesso. Campinas: Pontes Editores, 1988.

WINGATE, U. \& TRIBBLE, C. The Best of Both Worlds? Towards an EAP/Academic Literacies Writing Pedagogy. Studies In Higher Education, Vol. 37, No. 4, 06, p. 481-495, 2012. 
Artigo recebido em: 15 de agosto de 2015

Artigo aprovado em: 1 de setembro de 2015

\section{Sobre a autora:}

Raquel Salek Fiad possui graduação em Letras pela Universidade do Estado do Rio de Janeiro (1969), mestrado em Linguística pela Universidade Estadual de Campinas (1975) e PhD em Linguística pela State University of New York (1980). Atualmente é professora titular da Universidade Estadual de Campinas. Tem experiência na área de Linguística Aplicada, atuando principalmente nos seguintes temas: aquisição da escrita, letramento, ensino de português, formação de professores. É líder do Grupo de Pesquisa "Escrita: ensino, práticas, representações e concepções", cadastrado no CNPq. 